Protestantismo em Revista é licenciada sob uma Licença Creative Commons.

http://dx.doi.org/10.22351/nepp.v45i1.3197

\title{
Escavando o início da divinação israelita
}

\author{
Excavating the beginnings of Israelite divination
}

Silas Klein Cardoso*

\begin{abstract}
Resumo
O artigo explora o problema das origens do fenômeno profético do Israel antigo, problematizando a nomenclatura e delimitação desse fenômeno. A partir de análise de fontes arqueológicas epigráficas e de textos bíblicos, sugere-se que a nomenclatura é inadequada para conceber o conjunto de fenômenos tanto no Israel pré-exílico quanto exílico, visto que o termo $n \bar{a} b \hat{\imath}$ ', geralmente traduzido como "profeta" é mais amplo do que o campo semântico do termo português. Assim, são demonstradas dificuldades de encontrar arqueologicamente indícios para o papel profético no Israel antigo, os limites da terminologia para explicar o fenômeno e, por fim, é proposta uma avaliação da necromancia como fenômeno profético israelita no pósexílio.
\end{abstract}

Palavras-chave

Profecia. Profetismo. Necromancia. História da Religião de Israel. Exegese do Antigo Testamento.

\begin{abstract}
The article explores the origins of the prophetic phenomenon in ancient Israel, challenging the naming and delimitation of these phenomenon. It is proposed, from the analysis of epigraphic and exegetical sources, that the naming "prophetism" is inadequate for the characterization of the prophetical phenomenam in both stages of israelite history, pre and postexilic times, since the term nābî', usually rendered as "prophet" is wider than the portuguese term "profeta". Thus, we demonstrate the difficulties to find archaeological evidence for the prophetic role in ancient Isra-el, the limits of terminology to explain the phenomenon, and, finally, an evaluation of necroman-cy as an israeli prophetic phenomenon in post-exile.
\end{abstract}

Keywords

Prophecy. Prophetism. Necromancy. history of religion of Israel. Old Testament exegesis.

[Texto recebido em dezembro de 2017 e aceito em agosto de 2018, com base na avaliação cega por pares realizada por pareceristas ad hoc]

* Doutor em Ciências da Religião. E-mail: silasklein@gmail.com 


\section{Introdução}

O tema "origens e função do profetismo no Antigo Israel" traz sérias complicações, que talvez escapem aos desavisados. Primeiro, há grande dúvida na academia sobre o início de Israel. Sabe-se que em 1207 aEC já havia um povo de nome “Israel” em Canaan¹ e, talvez, uma inscrição recentemente descoberta ateste sua existência na metade do segundo milênio $\mathrm{aEC}^{2}$. Entretanto, responder o que era esse povo citado por Merneptah é complicado. A origem de Israel na terra é difícil de rastrear $^{3}$ e os inícios da monarquia israelita são

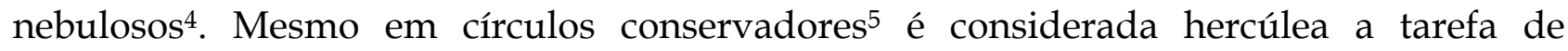
reconstruir a história israelita desde as evidências que dispomos, como arqueologia, iconografia, epigrafia e - por que não? - literatura bíblica. Cada fonte está limitada por seu plano de expressão e compõe-se por conceitos distintos de "passado", "legitimação", "documento", "cosmovisão" etc.

Se é difícil precisar o surgimento de Israel como todo - ou que seja como uma parte, como fez Finkelstein ${ }^{6}$ - , argumentar sobre o início da "profecia" ali é mais problemático. Primeiro, "profecia" é um conceito aglutinador: ele coloca sob um mesmo guarda-chuva uma série de fenômenos localizados cronológica e geograficamente, além de lidar com uma ampla gama de funções das sociedades antigas. Isso dá uma falsa impressão de

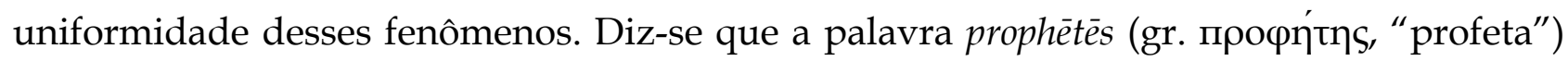
foi escolhida por significar "aquele que fala por um Deus"7. Entretanto, o termo grego diz muito mais que isso. Embora dicionários não sejam confiáveis, conferir o termo num

1 GRABBE, L.L. From Merneptah to Shoshenq: if we only have the Bible... In: GRABBE, L.L. (Org.) Israel in transition: from the Late Bronze II to Iron IIa (c. 1250-850 B.C.E). Volume 2: The Texts. New York; London: T\&T Clark, 2010a, p. 62-129.

2 VAN DER VEEN, P.; THEIS, C.; GÖRG, M. Israel in Canaan (long) before pharaoh Merenptah? A fresh look at Berlin Statue Pedestal Relief 21687. In: Journal of Ancient Egyptian Interconnections, vol. 2, n. 4, 2010, p. $15-25$.

3 Cf. MAZAR, Amihai. Archaeology of the land of the Bible 10,000-586 B.C.E. New Haven; London: Yale University Press, 1990; LEMCHE, N.P. Israel, history of: premonarchic period. In: FREEDMAN, D.N. (Org.). The Anchor Yale Bible Dictionary. Vol. 3. New York: Doubleday, 1992, p. 527-545; KILLEBREW, A.E. "The emergence of ancient Israel: the social boundaries of a "mixed multitude" in Canaan". In: MAEIR, A.M.; MIROSCHEDJI, P. (Eds.). "I will speak the riddles of ancient times". Archaeological and historical studies in honor of Amihai Mazar on the occasion of his sixtieth birthday. Winona Lake: Eisenbrauns, 2006, p. 555572. Para uma visão mais otimista, veja o texto de Arnold E Beyer. Os autores, porém, utilizam uma pesquisa de 1935 para dizer que a escavação de Jericó é inconclusiva, tornando seu argumento frágil. Cf. ARNOLD, B.T.; BEYER, B.E. Descobrindo o Antigo Testamento: uma perspectiva cristã. São Paulo: Cultura Cristã, 2001.

4 FINKELSTEIN, I. "The archaeology of the United Monarchy: an alternative view". In: Levant, vol. 28, p. 177-187, 1996, p. 177-187; FINKELSTEIN, I.; SILBERMAN, N.A. A Bíblia não tinha razão [the Bible Unearthed]. São Paulo: A Giraffa, 2003 [2001: ing]; KRATZ, R.G.; SPIECKERMANN, H. (Eds.). One God one cult one nation: archaeological and biblical perspectives. Berlin: De Gruyter, 2010.

5 P.ex., GARFINKEL, Y. "The davidic kingdom in light of the finds at Khirbet Qeiyafa". In: City of David studies of ancient Jerusalem. 2011, p. 6:13-35; ARNOLD, B.T.; HESS, R.S. Ancient Israel's history: an introduction to issues and sources. Grand Rapids: Baker, 2014.

6 FINKELSTEIN, I. The forgotten kingdom: the archaeology and history of northern Israel. Atlanta: SBL, 2013

7 NISSINEN, M. et al. Prophets and prophecy in the ancient Near East. WAW 12. Atlanta: Society of Biblical Literature, 2003, p. 5-6; NISSINEN, M. "What is Prophecy? An ancient Near Eastern perspective". In: KALTNER, J.; STULMAN, L. (Orgs.). Inspired speech: prophecy in the ancient Near East essays in honor of Herbert B. Huffmon. London: T\&T Clark, 2004, p. 17 
dicionário de grego clássico é elucidativo. A palavra pode significar: "oficial que guarda um oráculo", "membro de ordem de clérigos", "intérprete de presságios [mantis]”, "intérprete”, "arauto de jogos”, “curandeiro" etc ${ }^{8}$. Este termo não é suficiente para delimitar o fenômeno ao qual estamos tratando.

Mais problemático é lembrar que aplicar a designação "profecia” para Israel é, na melhor hipótese, economia de palavras e, na pior, um gigante anacronismo, mesmo quando aplicado como construção acadêmica. Se língua e metáforas estruturam o pensamento, como recentes teorias de linguagem afirmam ${ }^{9}$ devemos evidenciar o óbvio: o termo prophētēs é grego e, como tal, não compartilha as raízes semânticas e, por consequência, as categorias mentais do oeste semítico, berço do hebraico israelita. Chamar fenômenos israelitas de "profecia", portanto, seria imprecisão. Isso, porque é um processo tradutório que, como tal, perde nuances semânticas, tornando-se problemático. Além disso, é possível que a polarização entre fenômenos "proféticos", "mágicos" e "divinatórios", de forma geral, possa ser resultado da preconceituosa literatura protestante da primeira metade do século $X^{10}$ que, na tentativa de enfatizar a distinção das religiões ocidentais frente às orientais, criou categorizações inexatas.

Martin Nissinen e Jonathan Stökl11 discutiram recentemente o problema da conceituação de profecia no contexto do Antigo Oriente Próximo. Segundo eles, conceitos são processos interpretativos que enfatizam certas características e minimizam outras para encaixarem-se em propósitos ideológicos ou heurísticos. Assim, o conceito "profecia" varia de acordo com o contexto sócio-histórico, religioso ou acadêmico dos que o utilizam. Ao tratá-los no conceito do Antigo Oriente Próximo, os termos "profecia", "magia" e "divinação", tratariam da mesma esfera comunicacional entre seres sobrenaturais e naturais. A divinação, nesse ínterim, seria a busca/transmissão de conhecimento de seres sobrenaturais através de métodos ritualísticos ou não. Para Nissinen, há três pressupostos para a divinação: (1) faltam conhecimentos aos seres humanos sobre sua experiência de vida; (2) existem seres sobrenaturais que detém tais informações; (3) é possível acessar tais conhecimentos segundo agentes especializados ${ }^{12}$. A magia, em contraposição, trataria de aspectos mais práticos, buscando causar mudança ao paciente, seja maléfica ou benéfica, de forma preferivelmente ritualística.

8 LIDDELL, H.G. et al. A greek-english lexicon. Oxford: Clarendon Press, 1996, p. 1540.

9 LAKOFF, G.; JOHNSON, M. “Conceptual metaphor in everyday language”. In: The Journal of Philosophy, vol. 77, n. 8, aug. 1980, p. 453-486; LAKOFF, G; JOHNSON, M. Metaphors we live by: with a new afterword. Chicago: University of Chicago, 2003. [1980] [Kindle Edition]; University Press, 2010. [Kindle Edition]; LAUAND, J. "O sistema língua/pensamento árabe". In: LAUAND, J.; JOSGRILBERG, R. (Orgs.). Estudos em antropologia, religião e educação. São Paulo: Factash/CEMORrOc, 2015, p. 27-44.

10 Cf. DOUGLAS, M. Pureza e perigo. São Paulo: Perspectiva, 1976, p. 19-42; HAMORI, E.J. Women's divination in biblical literature: prophecy, necromancy and other arts of knowledge. New Haven: Yale, 2015, p. 3-18; NISSINEN, 2004, p. 21.

11 NISSINEN, M. Ancient Prophecy: Near Eastern, Biblical, and Greek Perspectives. Oxford: Oxford University Press 2017 [e-book]; cf. STÖKL, J. Prophecy in the ancient Near East: a philological and sociological comparison. Leiden: Brill, 2012, p. 7-11.

12 NISSINEN, 2017. 
Nessa linha de pensamento, a profecia faria parte de uma gama mais ampla de fenômenos divinatórios. Nissinen e Stõkl13, seguindo a tipologia clássica de Cícero em seu livro "De Divinatione", dividiram-nos em dois grandes grupos. O primeiro grupo é da divinação técnica, isto é, que poderia ser aprendida como um ofício e que se dava a partir da observação da natureza (2Sm 5.23-24) e animais (1Sm 6-7), sacrifício (Jz 13.19-23), objetos (Gn 44.5; 2Rs 13.14-19), sorteio (1Sm 10) etc. A divinação técnica teria como agentes o intérprete de sonhos e o agoureiro, por exemplo. O segundo grupo é da divinação intuitiva, cujo aprendizado não era requerido e poderia se dar a partir de sonhos (Gn 20.3; 37; 40; Jz 7.10-11), da consulta aos mortos (1Sm 28) e oráculos, de forma geral (1Sm 8; livros proféticos). A divinação intuitiva teria como agentes o sonhador e profeta, de forma geral. Entretanto, mesmo que possamos reconhecer os múltiplos tipos de "divinadores", tal superespecialização não transparece nem mesmo na pesquisa de Stökl, demonstrando que dependeríamos de uma delimitação maior para a compreensão do fenômeno divinatório. Dessa forma, acreditamos que ao mesmo tempo que é importante associar a divinação à uma gama maior de conceitos, é preferível traçar um percurso que demonstre não a unidade, mas a pluralidade de figurações do divinador.

Dessa forma, defendemos neste artigo que a verificação das origens e funções do profetismo em Israel exige dois passos. Primeiro, deve ser abandonado o conceito artificial de profecia. Por isso, sugerimos nomear esta gama de conceitos de "divinação", cuja carga semântica na língua portuguesa é mais ampla e não-taxativa. Segundo, objetivamos trabalhar prioritariamente em fontes internas, para que as fontes criem o conceito e não viceversa. Nossa metodologia, neste artigo, segue a mesma lógica de um processo de escavação: percorreremos as camadas mais próximas e iremos às camadas mais profundas. Como resultado, teremos resultados mais precisos nas camadas superiores e mais vagos nas camadas mais profundas. Essa dificuldade advém da própria formatação das evidências, que não tem por propósito conceituar o divinador, mas apenas utilizam a linguagem corrente de seu tempo. Dessa forma, desenterraremos três camadas de evidências, que demonstrarão que: (1) há evidências epigráficas do nāb̂̀' ("profeta") na Judah pré-exílica, ao contrário de teorias minimalistas correntes; (2) há terminologia própria para se ler o fenômeno no pré-exílio e, por isso, tais terminologias deveriam ser utilizadas na literatura acadêmica; e (3) há indícios de uma prática oracular javista multiforme na Bíblia Hebraica, que nos impede de chamar o fenômeno de "profecia".

\section{Evidências epigráficas do início da divinação israelita}

Embora existam outras fontes para a divinação no Oeste Semítico que talvez sejam próximas da divinação israelita, como os textos de Tell Deir 'Alla, a estela de Meša' e a estela

13 NISSINEN, 2017; STÖKL, 2012, p. 7-11. 
de Zakkur, essas são evidências externas, que só podem revelar a realidade israelita via analogia. E, caso sejam utilizadas, deve-se notar que há problemas mesmo na interpretação intratextual dessas fontes. No caso do reboque de Deir 'Alla, que cita o cognato $h z h$, mesmo que o texto pareça cooperar por analogia para uma data mais primitiva da escrita hebraica14, deve ser estressado que a evidência foi encontrada em estado fragmentário e sua reconstrução tem sido posta em dúvida ( $\operatorname{COS}^{15}$ 2.27). A estela de Meša', por sua vez, mesmo que utilizada para falar do aspecto, não menciona profetas ou atividade profética (cf. COS 2.23). E, por fim, a estela de Zakkur, que cita hôzzèh, "vidente", e o cognato do ugarítico 'ddn, "visionário", pode estar mencionando, simplesmente, "jovens"16 Além dessas dificuldades, esses artefatos trazem evidências tardias e de contexto moabita e egípcio, não israelita. Os únicos artefatos epigráficos que podem ser utilizados para falar do profetismo israelita préexílico são dois - talvez três - óstracos de Laquish (Tell ed-Duweir), respectivamente os óstracos de n. 3, 6 e 16, encontrados no nível da destruição de Nabucodonosor de 586 aEC ${ }^{17}$.

A inscrição n. 3 é extremamente curiosa, pois é dito que, numa carta prévia, Hoshaiah, tinha sido acusado de não saber ler, por não ter seguido as ordens prévias de Yaush, seu comandante em Laquish. Na parte de trás do óstraco há a menção a um profeta, que teria trazido uma mensagem dizendo: "cuidado". O termo para profeta é hnb', “o profeta", e sua menção com o artigo definido, demonstra ser um profeta em particular e reconhecido. O óstraco n.6, também é uma correspondência que, se traduzida corretamente, traz profunda ressonância com o texto de Jr 38.4, dizendo que o(s) profeta(s) proferiram

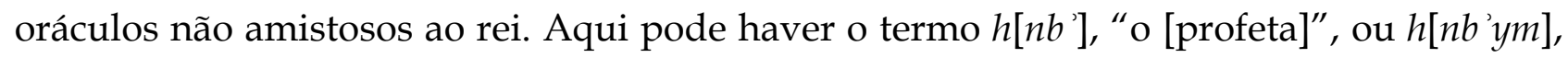
"os [profetas]", entretanto o óstraco está danificado demais para uma palavra final sobre o assunto.

Por fim, o fragmento 16 traz o termo $h n b$, , "o profeta", de forma clara, vindo logo após o termo bny, que pode significar "filhos de..." ou remeter a um nome próprio javista, como Benayahu (heb. bny[hw]). Assim, vemos que no momento da monarquia tardia judaíta,

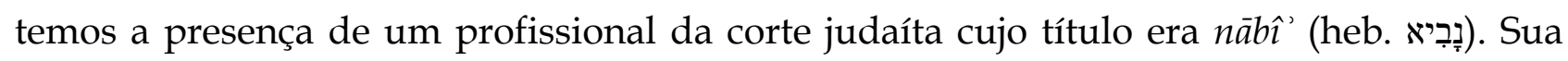
função parece ter sido de aconselhar o rei. Se a leitura do óstraco 6 for correta, eles também tinham a função de animar as tropas e é por isso que o rei os condena, por não estarem desempenhando bem seu papel nem em Jerusalém. Os oráculos eram distribuídos por cartas e, das reclamações do óstraco 6, parece que eram mantidos ipsis litteris, visto que seria mais fácil adulterá-los que reclamar.

14 P.ex., BLUM, E. “Die Kombination I der Wandinschrift vom Tell Deir Alla vorschläge zur rekonstruktion mit historisch-kritischen anmerkungen". In: KOTTSIEPER, I.; SCHMITT, R.; WÖHRLE, J. (Orgs.). Berührungspunkte. Studien zur sozial und religionsgeschichte Israels und seiner umwelt: FS Rainer Albertz. Münster: Ügarit-Verlag, 2008, p. 573-601.

15 Citação da obra: HALLO, W.W.; YOUNGER, K.L. The context of Scripture. Leiden; New York: Brill, 1997-, 3 vol.

16 NISSINEN, 2003, p. 204; COS 2.35.

17 NISSINEN, 2003, p. 212-218; COS 3.42. 


\section{Evidências terminológicas do início da divinação israelita}

Os óstracos de Laquish são tardios para falar do início da divinação em Israel. Seus textos descrevem a face burocrática da profecia na época da queda de Judah ${ }^{18}$, para o infortúnio dos idealizadores de profetas. Entretanto, eles nos levam a uma camada mais profunda, pois mostram a terminologia bíblica em uso no pré-exílio. E, se as inscrições Oeste Semíticas nos ajudam em algo, é em dizer que termos cognatos aos bíblicos também já existiam no segundo milênio aEC. Assim, a próxima camada se desvela na terminologia dos divinadores na Bíblia Hebraica.

O termo mais evidente é nābî̀ (heb. נְבְיא), que surge 316x no masculino e 6x no feminino. Cognatos do termo surgem em Ebla ${ }^{19}$, terceiro milênio aEC e em Emar ${ }^{20}$, Bronze Tardio, mas seu uso é distinto do hebraico bíblico. Em Ebla a raiz nabû $(m)$ significa "nomear, nomeação, decretar", o que, em listas léxicas, é igualado ao PÀ(D) sumério, que significa "encontrar/chamar". Não há atividade profética envolvida. Em Emar, o nabî é, aparentemente, adivinhador técnico. Entretanto, a deusa Ishara é incluída como munabiāti' e seu templo é chamado de "casa do nabı̂”". Assim, só podemos intuir que a palavra signifique "chamado" 21.

Na literatura bíblica, o $n \bar{a} b \hat{\imath}^{\prime}$ é retratado incoerentemente. Por um lado, há grupos de nĕbi 'îm, que geralmente recebem tal título pejorativamente (cf. 1Sm 10.10; 2Rs 3.13; 1Rs 18), cujas menções geralmente estão atreladas ao contexto de Israel Norte. Segundo Stökl22, há três caracterizações dos nĕbi '̂̀m: extáticos, adivinhadores técnicos e profetas escritores, este último sendo de desenvolvimento posterior em Israel. É notável que grupos de divinadores não aparecem em outro conjunto de textos do Antigo Oriente, a não ser na Bíblia. Alguns grupos são caracterizados como extáticos, como o "bando" que se juntou a Saul (1Sm 10.5, 10; 19.20). Mesmo que a caracterização do Saul-nāb̂̂̀' seja negativa, sendo primeiro sinal de eleição e depois de ruína (cf. 1Sm 19.20s 23 ), sabemos que a caracterização de Eliseu não é negativa na Bíblia Hebraica. Assim, corrobora à hipótese de existir transe nos oráculos o fato de Eliseu chamar um músico para ajudá-lo a atuar (2Rs 3.15) e, novamente de forma negativa, Oséias (9.7) equiparar o nābî̀ de Israel a um měšuggā',

18 Também STÖKL, 2012, p. 171.

19 Ebla (=Tell Mardikh). Cf. BIGGS, R.D. "Ebla Texts”. In: FREEDMAN, D. N. (Org.). The Anchor Yale Bible Dictionary. Vol. 2. New York: Doubleday, 1992, p. 263-270.

20 Emar (=Tell Meskene, sécs. XIV-XIII aEC) no Rio Eufrates. Cf. MARGUERON, J.C. "Emar". In: FREEDMAN, D. N. (org.).The Anchor Yale Bible Dictionary. New York: Doubleday, 1992, V.2, p. $489-496$.

21 STÖKL, 2012, p. 157-167; Cf. FLEMING, D. "Nābû and Munabbiātu: two new syrian religious personnel". In: Journal of the American Oriental Society, vol. 113, n. 2, abr/jun 1993, p. 175-183.

22 STÖKL, 2012, p. 174-175.

23 Cf. McKENZIE, S.L. "Saul in the Deuteronomistic History". In: EHRLICH, C.S.; WHITE, M.C. (Eds.). Saul in history and tradition. FAT 47. Tübingen: Mohr Siebeck, 2006, p. 59-70; FOKKELMAN, J. "The Samuel composition as a book of life and death: structural, generic and numerical forms of perfection". In: AULD, Graeme; EYBIKEL, E. (Eds.). For and against David. BETL 232. Leuven: Peeters, 2010, p. 15-46. 
"enlouquecido". Nos três textos o transe está ligado à rûaḥ" , "espírito/vento", provavelmente denominando possessão divina ${ }^{25}$.

Quanto a indivíduos, há dúvidas se Oséias era chamado nāb̂̀ '26 e Amós, de forma contundente, rejeita o título. Também é suspeito que o livro de Isaías (1.1) inicie dizendo: “visão [hāzōww] de Isaías Ben-Amoz, que ele viu [hāâa]...", o que pode sugerir que, no préexílio, se identificassem como hạzî̀m, não nĕbi îm. Quanto a mulheres27, o único título profético atribuído é, justamente, nĕbî'â, "profetiza". Hulda e Deborah aqui formam o retrato mais habitual28: elas são nĕb̂ै' $\hat{a}$, ponto. Os textos não trazem contendas quanto a gênero, demonstrando que era comum a função, apesar das poucas citações ${ }^{29}$. Destas informações, é possível tanto supor que o termo nāb̂̀' retrate um fenômeno amplo, quanto dizer que o vocábulo teve mais de um significado no decorrer dos séculos. O que se pode dizer por certo é que nĕbi î̀m eram oficiais dos reis ${ }^{30}$.

O termo hạze (heb. Tîn) tem formato de qal particípio, denotando uma pessoa que habitualmente faz algo e também parece ter sido título de oficial, visto que das 16x que surge, $11 x$ estão ligadas à corte ${ }^{31}$. Pode-se intuir que houvesse amplo uso do vocábulo, visto que muitos oráculos trazem a palavra hạzōonn e, também, há uma inscrição do título num selo egípcio (UC 51354) de Deir Rifa, que também atestaria o uso da palavra na inscrição lqn $h z$, i.e., "pertencente a Qn, o vidente/visionário"32. Uma tradução possível seria "visionário", por ser ligado à raiz de "ver, perceber". São denominados como hōze: Asafe, Gade, Hemã, Ido, Jeú Ben-Hanani e, talvez, Jedutum. Três desses eram líderes do templo. Assim, juntamente à evidência de sua ligação à corte, parece que os hōzîm eram funcionários do Segundo Templo e, possivelmente, músicos (1Cr 25).

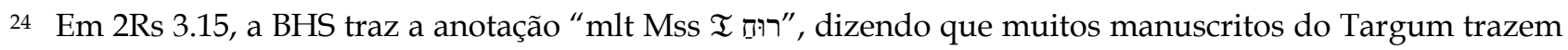
esse termo no lugar de "’-", que poderia ser traduzido como "mão" ou "poder".

25 Uma hipótese considerada é que esses textos tragam uma interpretação pós-exílica dos něbi îm, pois os grupos musicais também eram reconhecidos como nĕbi î̀m (Cf. 1Cr 25). Entretanto, não parece ser o caso dos textos, pois todos eles se referem ao Israel Norte, o que não coadunaria com tal editoração dos textos.

26 Há camadas redacionais que excluiriam as menções. Cf. STÖKL, 2012, p. 185.

27 Em Mari há a figura do "homem-mulher", assinnu, que seria um profeta de duplo gênero.

28 I.e., são bem projetadas na história, são factíveis. Cf. ACKERMAN, S. “Digging up Deborah: recent Hebrew Bible scholarship on gender and the contribution of archaeology". In: Near Eastern Archaeology, vol. 66, n. 4, 2003, p. 172-184; GAFNEY, W. Daughters of Miriam: women prophets in ancient Israel. Minneapolis: Fortress, 2008.

29 Entretanto, esse não é o caso dos intérpretes. Hamori (2015, p. 186-192) demonstra que a interpretação delas foi marginalizada pelos tradutores e intérpretes bíblicos, que retroprojetam seus problemas com o gênero contemporâneo ao texto bíblico. Cf. também WILLIAMSON H. G. M. "Prophetesses in the Hebrew Bible". In: DAY, J. (Ed.). Prophecy and the prophets in ancient Israel. LHB/OTS 531. New York: T\&T Clark, 2010, p. 65-80. Em Mari, mulheres eram profetizas, entretanto, quanto maior o status, menor o número de mulheres e, no Império Neo-Assírio, havia um número parecido de mulheres e homens. Cf. S STÖKL, J. "Female prophets in the ancient Near East". In: DAY, J. (Ed.). Prophecy and the prophets in ancient Israel. LHB/OTS 531. New York: T\&T Clark, 2010, p. 47-61.

30 Talvez Is 3.1-7 forneça uma boa dica para o caso, onde ele lista oficiais e, entre eles, cita o nābî' e o qsm (adivinho). Jr 3.2; 29.8 (cf. Dt 18.10) também trazem-no em lista de oficiais. Stökl (2012, p. 179-186) diz que há aumento do uso no exílio, especialmente na literatura de Jeremias.

31 STÖKL, 2012, p. 193-194.

32 STÖKL, 2012, p. 22-23. 
O vocábulo rō'e (heb. רֶֶ) também pode ser traduzido como "vidente", sendo idêntico à palavra "ver" (heb. rō'e), mas talvez tenha o sentido de "sensitivo", como dono de percepção extra-sensorial. Ele surge 11x e é notável que cinco sejam referências a Samuel (1Sm 9.9; 1 Cr 9.22; 26.28; 29.29). Além dele, apenas Hanani (2Cr 16.7) é chamado rō'e. Isso faz pensar que haja memória histórica envolvida ${ }^{33}$. Entretanto, os diferentes extratos da narrativa não cooperam à caracterização da função, que talvez denote a divinação desinstitucionalizada ${ }^{34}$.

Argumentamos, que nābî', něblì â e hōze eram títulos de cargos divinatórios que compunham o corpo de oficiais da corte judaíta (e israelita) no pré-exílio. Sua função era aconselhar reis e animar tropas. Suas mensagens vinham de oráculos provavelmente extáticos, registrados em documentos e enviados por mensageiros. rōe parece ter sido designação do divinador amador. O que se vê claramente é que Israel viveu com várias formas de divinação.

\section{Evidências indiciárias do início da divinação israelita}

Isso nos leva à camada mais profunda. Até agora, os perfis proféticos desde a queda de Judah à Babilônia até o antigo Israel Monárquico se mostraram bastante similares aos outros fenômenos do Antigo Oriente Próximo. Como se sabe, Mari e os Neo-Assírios tinham no muhh ûm o extático do culto (de mahh $\hat{u}$, tornar-se louco) ${ }^{35}$, assim como Israel tinha seus nĕbi î̀m. De igual modo, Mari tinha o ap̃ilum como porta-voz/tradutor da divindade, tal qual os israelitas tinham seus ḥōzîm. Esta ligação também pode compreender o cognato nāb̂̀', caso se confirme a ligação ao nabûu(m) de Ebla e o nabî de Emar. Entretanto, esses termos nos fazem a religião israelita parecer burocrática e, imaginativamente oficial, que só foi tão coesa na idealização dos redatores $\operatorname{tardios}^{36}$.

Aqui precisamos fazer um excurso. Hoje já não convém ler a religião israelita com a distinção entre "oficial" e "popular", visto que este é um termo que marca mais a presença e pertença religiosa dos intérpretes do que a presença de evidências histórico-filológicas ${ }^{37}$. Já foram, inclusive, sugeridos outros modelos, como: (1) a tríade de Albertz ${ }^{38}$, que envolveria a religião "oficial”, a religião familiar/tribal e a religião dos santuários locais (2)

33 CARDOSO, S.K. Antigos retratos de uma esquecida monarquia do Norte: uma leitura exegética em 1Sm 9.15-25. 2016 [artigo não publicado]; STÖKL, 2012, p. 196-200.

34 STÖKL, 2012, p. 199.

35 NISSINEN, 2003, p. 6-8; STÖKL, 2012, p. 29-154.

36 Para Bloch-Smith (1992, p. 131-132) foi só das reformas de Ezequias e Josias, combinadas a falas proféticas (p.ex., Isaías), que foram criados tabus concernentes ao contato com mortos, por exemplo.

37 STAVRAKOPOULOU, F. "Popular" religion and "official" religion: practice, perception, portrayal". In: STAVRAKOPOULOU, F.; BARTON, J. Religious diversity in ancient Israel and Judah. London: Bloomsbury T\&T Clark, 2013, p. 37-58.

38 ALBERTZ, R. Historia de la religión de Israel en tiempos del Antíguo Testamento. 2 vols. Madrid: Editorial Trotta, 1999. 
o modelo sócio-religioso de Ziony Zenit ${ }^{39}$, que envolve os termos hebraicos para as diversas classificações sociais: geber, bayit, mispaha, sebet,' am. Em paralelo à quebra da dicotomia "religião oficial vs religião popular", hoje há evidência suficiente para colocar em cheque qualquer ideia sobre centralização dos cultos ${ }^{40}$. Hoje há hipóteses, como a de Albertz e Schmitt ${ }^{41}$, que chegam a dividir em oito os espaços de culto israelita no Período do Ferro ${ }^{42}$ : (1) culto doméstico; (2) cultos do trabalho; (3) santuários de vizinhança; (4) locais de culto para os mortos; (5) santuários de vilas; (6) santuários de palácios; (7) santuários regionais com sacerdotes; (8) santuários supra-regionais para o culto oficial. Cada um destes teria seu próprio público, corpo de oficiantes e mesmo ritos e cerimônias realizadas, desafiando teorias mais antigas da história da religião de Israel $^{43}$. Nesse novo panorama exegético, devemos observar o fenômeno divinatório de forma mais ampla e menos taxativa.

Em nossa opinião, um bom exemplo para a percepção da divinação israelita como um fenômeno mais amplo é a prática da necromancia, que está mais espalhada pelas páginas bíblicas do que se assume. Tais cultos necromânticos tinham forte relação com os patriarcas e matriarcas familiares ${ }^{44}$, assim como tinham por papel social a reivindicação de terras $^{45}$. Avesso às contendas posteriores (p.ex. Lv 19.31; 20.6; Dt 18.11), é interessante notar que no exílio a necromancia ainda é praticada. Em Ez 13.17-23 há a estranha menção às "filhas do teu povo que hammitěnabbe 'ōwt ["profetizam"] do coração delas". Esse ciclo é a parte feminina da condenação de Ez 13.1-16. Enquanto Em Ez 13.1-16 o alvo são os nĕbî' $\hat{e}$ yiśrāèl, "profetas de Israel", aqui a fala está direcionada às "filhas do povo que hammitěnabbě 'ôwt", i.e., "profetizam". Há diversos aspectos notáveis nesse texto. Primeiro, é interessante que não é a prática da divinação que é condenada, mas o fato do resultado vir "da imaginação delas" ou, no hebraico, "do coração". Isto é, não há contenda quanto a legitimidade do movimento e sim quanto a interpretação do fenômeno divinatório, que vem das próprias opiniões e interesses dessas mulheres. O termo para o ato de "profetizar" é tão válido quanto o cargo daqueles citados no início do capítulo.

39 ZEVIT, Ziony. The religions of ancient Israel: a synthesis of parallactic approaches. New York: Continuum, 2001.

40 UEHLINGER, C. "Distinctive or diverse? Conceptualizing ancient israelite religion in its southern levantine setting". In: Hebrew Bible and Ancient Israel, vol. 4, p. 1-24, 2015.

41 ALBERTZ, R.; SCHMITT, R. Family and household religion in ancient Israel and the Levant. Winona Lake: Eisenbrauns, 2012.

42 Para uma tentativa de visualização da diversidade de formas comunicativas do Antigo Israel de acordo com a tipologia de Albertz e Schmitt, cf. CARDOSO, S. K. “Práticas comunicativas nos tempos do Antigo Testamento: iluminando novas (propostas) homiléticas”. In: Tear Online, v.6, n.2, jul/dez 2017, p. 102-115.

43 HARAN, M. Temples and temple-service in ancient Israel: an inquiry into the character of cult phenomena and the historical setting of the P. Oxford: Clarendon, 1978.

44 NIDITCH, Susan. Ancient israelite religion. New York: Oxford University Press, 1997, p. 63-69; NIDITCH, Susan. "Experiencing the divine: heavenly visits, earthly encounters and the land of the dead". In: STAVRAKOPOULOU, F.; BARTON, J. Religious diversity in ancient Israel and Judah. London: Bloomsbury T\&T Clark, 2013, p. 11-22.

45 STAVRAKOPOLOU, F. Land of our fathers: the roles of ancestor veneration in bíblical land claims. New York: Bloomsbery, 2012. 
Segundo, é interessante observar que sua forma de adivinhação é “caçar nĕpāšōwt ["mortos/fantasmas?"] como aves" (lěpōrĕhōwt, v.20). Se a figura parece exótica para nós, ela não era no contexto do Antigo Oriente Próximo. "Ave" é uma forma comum para se referir a mortos em Ugarit. Também, não é coincidência que em Emar seja o primeiro local para a aparição da raiz traduzida por "profeta/profetizar". Ali, os termos utilizados são munabbiātu, no feminino, que aparecem quatro vezes e, no masculino nabi, surgindo oito vezes. Nos oito casos do termo masculino há relação com os mortos, enquanto no feminino há a conotação de invocação aos mortos ${ }^{46}$. De igual modo, a referência à caça das nĕpāšōwt, pode trazer o significado de ancestrais mortos ou mesmo fantasmas ${ }^{47}$. Tudo isso implicaria que a forma "profetizar" (hammitěnabbĕ ōwt) dessas mulheres, que era autorizada e aprovada por Ezequiel, era uma forma de necromancia, o que implicaria que, para Ezequiel, a necromancia era "profecia" e que esse conceito parte das fontes anteriores à profecia bíblica.

Sendo este o caso, talvez possa ser contraposto que esta era uma prática singular e que não caracterizaria o fenômeno maior da divinação israelita. Entretanto, podemos alocar essas "mulheres que hammitĕnabbĕ 'ōwt" ao lado de uma série de outras mulheres da literatura bíblica que formam um retrato mais amplo da divinação no início de Israel Norte. Essas mulheres se juntam a: (1) 'ēšet ba ălat-'ōwb, que é geralmente chamada de "necromante de En-Dor". Esta mulher, no texto bíblico, é o canal para a profecia javista final de Samuel (1Sm 28.16-17!). Há tantos problemas com essa concepção no Israel pós-exílico, que o cronista teve que atribuir a sua consulta à lista dos "pecados" de Saul (cf. 1Cr 10.13). Elas também se juntam a (2) Raquel, matriarca benjaminita, que utiliza o(s?) těrāpîm (Gn 31.19). Esses těrāpîm eram, muito provavelmente, imagens de culto dos ancestrais mortos ${ }^{48}$. Assim como Raquel, (3) Mical, filha de Saul, também utiliza tĕrāpîm para esconder Davi (1Sm 19.13). E, por fim, (4) a mãe de Mica, que financia o těrāpîm, feito para Javé (!), de seu filho (Jz 17.3). Essas evidências, reunidas em torno de mulheres e dos cultos aos mortos nos ajudam a perceber três coisas: (a) havia culto aos mortos/ancestrais em Israel; (b) esse culto aos mortos não era proibido a princípio, visto figurar no próprio palácio do rei; (c) os těrāpîm eram parte presente do aparato cúltico norte-israelita, talvez como uma prática divinatória doméstica. Essa prática divinatória doméstica pode ser contraposta a itens bem reconhecidos que faziam parte do aparato cúltico estatal, como a própria arca da aliança, objeto divinatório nos tempos de Saul (1Sm 23.6, 9; 30.7) ${ }^{49}$.

46 STÖKL, J. “The מתנבאותin Ezekiel 13 reconsidered”. In: Journal of Biblical Literature, vol. 132, n. 1, p. 61-76, 2013; STÖKL, 2012, p. 159-167; HAMORI, 2015, p. 170-171.

47 HAMORI, 2015, p. 172.

48 TOORN, K.V.D. "The nature of the biblical teraphim in the light of the cuneiform evidence". In: $C B Q$, vol. 52, n. 2, p. 203-222, abr 1990; HAMORI, 2015, p. 189-202.

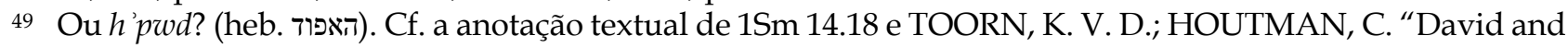
the ark". In: Journal of Biblical Literature, vol. 113, n. 2, p. 209-231, 1994. 


\section{Considerações finais}

Há, portanto, fortes indícios de que a divinação era um fenômeno mais amplo e com mais nuances do que geralmente se aceita na academia. Na sede de salvar o texto para os leitores modernos, interditam-se conceitos e práticas consideradas heterodoxas, para que as traduções limitem a pluralidade de sentidos dos nĕbi'îm israelitas. Num olhar mais aproximado, vemos que o próprio texto bíblico ora contrapõe a profecia e necromancia (p.ex. Lv 19.31; 20.6; Dt 18.11) e ora as demonstra como pares (Ez 13). Nos negamos, portanto, a chamar os nābl', ḩozze e rō 'e de profetas neste artigo. Nosso intuito foi demonstrar que o conceito "profecia" não é capaz de lidar com as origens e nem com as funções dos fenômenos divinatórios israelitas.

Assim, a partir da análise das fontes conjuntas, especialmente das fontes epigráficas, demonstramos os limites para a exploração do fenômeno a partir do texto bíblico isolado. Como provocação, mostramos que se escavarmos fundo, há indícios de uma necromancia javista aceita como "profecia" ainda no exílio. Isso significa que a profecia era heterodoxa aos nossos conceitos modernos. Sim, profetas eram oficiais como vimos em Laquish, mas também eram mágicos e xamãs como Elias e Eliseu ${ }^{50}$ e até necromantes. Ao que parece, surgiram nas montanhas de Efraim, como as histórias mais antigas corroboram, estas que foram interditadas na redação posterior da História de Israel. De qualquer forma, torna-se evidente a necessidade de utilizarmos múltiplas fontes para a reconstrução da História de Israel e da Religião de Israel.

\section{Referências}

ACKERMAN, S. Digging up Deborah: recent Hebrew Bible scholarship on gender and the contribution of archaeology. In: Near Eastern Archaeology, vol. 66, n. 4, p. 172-184, 2003.

ALBERTZ, R. Historia de la religión de Israel en tiempos del Antíguo Testamento. 2 vols. Madrid: Editorial Trotta, 1999.

ALBERTZ, R.; SCHMITT, R. Family and household religion in ancient Israel and the Levant. Winona Lake: Eisenbrauns, 2012.

ARNOLD, B.T.; BEYER, B.E. Descobrindo o Antigo Testamento: uma perspectiva cristã. São Paulo: Cultura Cristã, 2001.

ARNOLD, B.T.; HESS, R.S. Ancient Israel's history: an introduction to issues and sources. Grand Rapids: Baker, 2014.

50 Eles controlam a água (1Rs 17.1; 18.1, 41-45), fazem jornadas miraculosas (1Rs 18.46), chamam comida do além, curam e ressuscitam mortos (1Rs 17; 2 Rs 4) e retomam objetos perdidos (2Rs 6.1-7). Para uma exploração de Elias e Eliseu como xamãs e mágicos, cf. GRABBE, L.L. "Shaman, preacher, or spirit medium? The israelite prophet in the light of antropological models". In: DAY, J. (Ed.). Prophecy and the prophets in ancient Israel. New York: T\&T Clark, 2010b, p. 117-132. 
BIGGS, R.D. Ebla Texts. In: FREEDMAN, D. N. (Org.). The Anchor Yale Bible Dictionary. Vol. 2. New York: Doubleday, 1992. p. 263-270.

BLUM, E. Die Kombination I der Wandinschrift vom Tell Deir Alla vorschläge zur rekonstruktion mit historisch-kritischen anmerkungen. In: KOTTSIEPER, I.; SCHMITT, R.; WÖHRLE, J. (Orgs.). Berührungspunkte. Studien zur sozial und religionsgeschichte Israels und seiner umwelt: FS Rainer Albertz. Münster: Ügarit-Verlag, 2008. p. 573-601.

CARDOSO, S.K. Antigos retratos de uma esquecida monarquia do Norte: uma leitura exegética em 1Sm 9.15-25. 2016. [artigo não publicado]

CARDOSO, S. K. Práticas comunicativas nos tempos do Antigo Testamento: iluminando novas (propostas) homiléticas. In: Tear Online, v.6, n.2, p. 102-115, jul./dez. 2017.

DOUGLAS, M. Pureza e perigo. São Paulo: Perspectiva, 1976.

FINKELSTEIN, I. The archaeology of the United Monarchy: an alternative view, Levant, vol. 28, p. 177-187, 1996.

FINKELSTEIN, I. The forgotten kingdom: the archaeology and history of northern Israel. Atlanta: SBL, 2013.

FINKELSTEIN, I.; SILBERMAN, N.A. A Bíblia não tinha razão [the Bible Unearthed]. São Paulo: A Giraffa, 2003 [2001: ing]

FLEMING, D. Nābû and Munabbiātu: two new syrian religious personnel. In: Journal of the American Oriental Society, vol. 113, n. 2, p. 175-183, abr./jun. 1993.

FOKKELMAN, Jan. The Samuel composition as a book of life and death: structural, generic and numerical forms of perfection. In: AULD, Graeme; EYBIKEL, E. (Eds.). For and against David. BETL 232. Leuven: Peeters, 2010. p. 15-46.

GAFNEY, W. Daughters of Miriam: women prophets in ancient Israel. Minneapolis: Fortress, 2008.

GARFINKEL, Y. The davidic kingdom in light of the finds at Khirbet Qeiyafa. In: City of David studies of ancient Jerusalem. 2011. p. 6:13-35.

GRABBE, L.L. From Merneptah to Shoshenq: if we only have the Bible.... In: GRABBE, L.L. (Org.) Israel in transition: from the Late Bronze II to Iron IIa (c. 1250-850 B.C.E). Volume 2: The Texts. New York; London: T\&T Clark, 2010a. p. 62-129.

GRABBE, L.L. Shaman, preacher, or spirit medium? The israelite prophet in the light of antropological models. In: DAY, J. (Ed.). Prophecy and the prophets in ancient Israel. New York: T\&T Clark, 2010b. p. 117-132.

HAMORI, E.J. Women's divination in biblical literature: prophecy, necromancy and other arts of knowledge. New Haven: Yale, 2015.

HARAN, M. Temples and temple-service in ancient Israel: an inquiry into the character of cult phenomena and the historical setting of the P. Oxford: Clarendon, 1978. 
KILLEBREW, A.E. The emergence of ancient Israel: the social boundaries of a "mixed multitude" in Canaan. In: MAEIR, A.M.; MIROSCHEDJI, P. (Eds.). "I will speak the riddles of ancient times". Archaeological and historical studies in honor of Amihai Mazar on the occasion of his sixtieth birthday. Winona Lake: Eisenbrauns, 2006. p. 555-572.

KOVECSES, Zoltán. Metaphor: a practical introduction. 2. ed. New York: Oxford University Press, 2010. [Kindle Edition]

KRATZ, R.G.; SPIECKERMANN, H. (Eds.). One God one cult one nation: archaeological and biblical perspectives. Berlin: De Gruyter, 2010.

LAKOFF, G; JOHNSON, M. Metaphors we live by: with a new afterword. Chicago: University of Chicago, 2003. [1980] [Kindle Edition]

LAKOFF, G.; JOHNSON, M. Conceptual metaphor in everyday language. In: The Journal of Philosophy, vol. 77, n. 8, aug. 1980. p. 453-486.

LAUAND, J. O sistema língua/pensamento árabe. In: LAUAND, J.; JOSGRILBERG, R. (Orgs.). Estudos em antropologia, religião e educação. São Paulo: Factash/CEMORrOc, 2015. p. 27-44.

LEMCHE, N.P. Israel, history of: premonarchic period. In: FREEDMAN, D.N. (Org.). The Anchor Yale Bible Dictionary. Vol. 3. New York: Doubleday, 1992. p. 527-545.

LIDDELL, H.G. et al. A greek-english lexicon. Oxford: Clarendon Press, 1996.

MARGUERON, J.C. Emar. In: FREEDMAN, D. N. (Org.).The Anchor Yale Bible Dictionary. New York: Doubleday, 1992, V.2. p. 489-496

MAZAR, Amihai. Archaeology of the land of the Bible 10,000-586 B.C.E. New Haven; London: Yale University Press, 1990.

McKENZIE, S.L. Saul in the Deuteronomistic History. In: EHRLICH, C.S.; WHITE, M.C. (Eds.). Saul in history and tradition. FAT 47. Tübingen: Mohr Siebeck, 2006. p. 59-70.

NIDITCH, Susan. Ancient israelite religion. New York: Oxford University Press, 1997

NIDITCH, Susan. Experiencing the divine: heavenly visits, earthly encounters and the land of the dead. In: STAVRAKOPOULOU, F.; BARTON, J. Religious diversity in ancient Israel and Judah. London: Bloomsbury T\&T Clark, 2013. p. 11-22.

NISSINEN, M. et al. Prophets and prophecy in the ancient Near East. WAW 12. Atlanta: Society of Biblical Literature, 2003.

NISSINEN, M. What is Prophecy? An ancient Near Eastern perspective. In: KALTNER, J.; STULMAN, L. (Orgs.). Inspired speech: prophecy in the ancient Near East essays in honor of Herbert B. Huffmon. London: T\&T Clark, 2004. p. 17-37.

STÖKL, J. Female prophets in the ancient Near East. In: DAY, J. (Ed.). Prophecy and the prophets in ancient Israel. LHB/OTS 531. New York: T\&T Clark, 2010. p. 47-61. 
STÖKL, J. Prophecy in the ancient Near East: a philological and sociological comparison. Leiden: Brill, 2012.

STÖKL, J. “The מתנתבאות Ezekiel 13 reconsidered”. In: Journal of Biblical Literature, vol. 132, n. 1, p. 61-76, 2013

STAVRAKOPOLOU, F. Land of our fathers: the roles of ancestor veneration in bíblical land claims. New York: Bloomsbery, 2012.

STAVRAKOPOULOU, F. "Popular" religion and "official" religion: practice, perception, portrayal". In: STAVRAKOPOULOU, F.; BARTON, J. Religious diversity in ancient Israel and Judah. London: Bloomsbury T\&T Clark, 2013, p. 37-58.

TOORN, K.V.D. The nature of the biblical teraphim in the light of the cuneiform evidence. In: $C B Q$, vol. 52, n. 2, p. 203-222, abr. 1990

TOORN, K. V. D.; HOUTMAN, C. David and the ark. In: Journal of Biblical Literature, vol. 113, n. 2, p. 209-231, 1994.

UEHLINGER, C. Distinctive or diverse? Conceptualizing ancient israelite religion in its southern levantine setting. In: Hebrew Bible and Ancient Israel, vol. 4, p. 1-24, 2015.

VAN DER VEEN, P.; THEIS, C.; GÖRG, M. Israel in Canaan (long) before pharaoh Merenptah? A fresh look at Berlin Statue Pedestal Relief 21687. In: Journal of Ancient Egyptian Interconnections, vol. 2, n. 4, p. 15-25, 2010.

WILLIAMSON H. G. M. Prophetesses in the Hebrew Bible. In: DAY, J. (Ed.). Prophecy and the prophets in ancient Israel. LHB/OTS 531. New York: T\&T Clark, 2010. p. 65-80.

ZEVIT, Ziony. The religions of ancient Israel: a synthesis of parallactic approaches. New York: Continuum, 2001. 